\title{
Airflow in unilateral vocal cord paralysis before and after Teflon injection
}

\author{
Y. CORMIER ${ }^{1}$, H. KASHIMA, W. SUMMER, AND H. MENKES
}

From the Respiratory Division of the Department of Medicine and the Department of Laryngology and Otology of the Johns Hopkins University School of Medicine, Baltimore, Maryland, USA

Cormier, Y., Kashima, H., Summer, W., and Menkes, H. (1978). Thorax, 33, 57-61. Airflow in unilateral vocal cord paralysis before and after Teflon injection. The effect of unilateral vocal cord paralysis and intracordal Teflon injection on maximum expiratory and inspiratory flows was studied in 15 consecutive patients. Ten patients had a ratio of forced expiratory flow to forced inspiratory flow at $50 \%$ vital capacity $\left(\dot{\mathrm{Ve}}_{50} / \dot{\mathrm{V}} \mathrm{i}_{50}\right)$ more than one. Of the remaining five, four had low $\dot{\mathrm{V}} \mathrm{e}_{50}$ consistent with underlying bronchial disease. Repeat studies were obtained in 10 patients two or more weeks after Teflon injection into a vocal cord for voice therapy. Maximum expiratory flow rates did not change (means $6 \cdot 64 \pm 0.881 / \mathrm{sec}$ before and $6 \cdot 47 \pm 1 \cdot 10 \mathrm{l} / \mathrm{s}$ after injection). Inspiratory flow at $50 \%$ vital capacity improved in all six patients with a forced expiratory volume in one second $\left(\mathrm{FEV}_{1}\right)$ greater than $75 \%$ of the forced vital capacity (FVC). In patients with an $\mathrm{FEV}_{1}$ less than $75 \% \mathrm{FVC}$, no consistent changes could be seen. We conclude that a high $\dot{\mathrm{V}} \mathrm{e}_{50} / \dot{\mathrm{V}}_{50}$ suggestive of variable extrathoracic airways obstruction is a frequent finding in the presence of unilateral vocal cord paralysis. Teflon injection does not cause a significant reduction in forced expiratory flows and improves inspiratory flows in subjects without evidence of underlying bronchial disease.

Bilateral vocal cord paralysis is a well-documented cause of variable extrathoracic airways obstruction (Miller and Hyatt, 1973; Yernault et al., 1973). The effect of unilateral vocal cord paralysis on airflows is poorly documented (Shim et al., 1972). Schiratzki (1965) reported an increase in mouth to subglottic resistance in females with unilateral recurrent nerve paralysis although he found no increase in males. Physiological studies after Teflon injection have not, to our knowledge, been reported.

The injection of Teflon into a vocal cord for vocal rehabilitation of paralytic dysphonia was first reported by Arnold (1961). This technique has now become the treatment of choice for symptoms of permanent unilateral vocal cord paralysis. The object of the procedure is to improve vocal function and reduce aspiration. Enough Teflon paste is injected into the paralysed cord to create a rigid structure against which the normal vocal cord opposes during phonation. Results have been excellent (Lewy, 1963, 1976; Rubin, 1965a, b), with voice improvement reported in up to $96 \%$ of patients, and similar success

${ }^{1}$ Fellow, American Lung Association in reducing the evidence of aspiration (Dedo et al. 1973; Rontal et al., 1976).

Complications have been rare and usually transient. Occasional mild stridor can occur after the injection; this is attributed to oedema and usually regresses in a few days. Reactive oedema sufficient to require tracheostomy is rare. The reported cases of acute airways obstruction were not documented by airflow studies.

The long-term effect of this foreign body on airflows has not been evaluated. Does the injection of Teflon into a paralysed vocal cord compromise the functions of the vocal box as an airway? To answer this question, and to clarify the physiological effect of unilateral vocal cord paralysis on maximal airflows, we describe airflow studies in 15 patients with unilateral vocal cord paralysis, 10 of whom underwent Teflon injection.

\section{Material and methods}

Nineteen consecutive patients referred to The Johns Hopkins Hospital Otolaryngology Service with unilateral vocal cord paralysis were studied. Four 
patients in whom we were unable to obtain reproducible data were eliminated from the study. The remaining 15 patients are reported in this paper. Ten patients were available for study after Teflon injection, one had spontaneous recovery, two refused injection, and two were lost to follow-up.

Measurements of forced inspiratory and expiratory flows were performed with a waterless spirometer (CPI model 220). Flow volume loops were stored on an oscilloscope and transcribed onto graph paper with an oscillotracer. All values were corrected to BTPS. Results presented are the highest values from three reproducible forced respiratory manoeuvres. Teflon injections were performed by one of us (HK). The patients were admitted to hospital and the injection was performed while laryngeal exposure was maintained by Suspension Laryngoscopy. Topical anaesthesia (4\% xylocaine) was used and supplemented by intravenous diazepam. Teflon paste, $0 \cdot 2-0.6 \mathrm{ml}$, was injected with a Bruning syringe into the mid-portion of the membraneous vocal cord until the desired vocal cord contour was achieved (Arnold, 1961). The laryngoscope was withdrawn and the patient's voice checked. Mirror laryngoscopy was performed to verify that the vocal cords approximated during phonation. When necessary, the direct laryngoscopy was repeated for supplemental injection. The patient was asked to rest his voice and was discharged from hospital on the morning after the operation. Post-injection studies were obtained two or more weeks after the Teflon injection.

\section{Results}

Clinical data are presented in Table 1. Presenting $\frac{\overline{0}}{\overline{0}}$ symptoms were usually those of hoarseness. Five $\overrightarrow{\mathbb{D}}$ patients also complained of aspiration. Most patients noted shortness of breath while speaking. Of the $10 \mathrm{w}$ patients who received Teflon injection and were $\vec{\circ}$ available for follow-up, none had clinically apparent acute airways obstruction after injection. All patients $\vec{\omega}$ who complained of aspiration before the injection claimed relief after the procedure. Good subjective $x$ voice improvement was achieved in seven of the $10 \mathrm{~W}$ patients.

Results of pulmonary function tests are presented in Table 2. The patients are listed in order of increas-응 ing $\mathrm{FEV}_{1} \%$. Five patients had spirometric evidence of underlying disease. Four had airways obstruction Th with an FEV $1 / F V C$ less than $70 \%$ and one (LS) had aO reduced forced vital capacity probably secondary to previous resective surgery for histoplasmosis.

The significance of functional changes following Teflon injection was assessed with the standard $t$ test. In the group as a whole a significant improvement $(\mathrm{P}<0.05)$ of forced expiratory flows at $50 \%$ vitalo capacity $\left(\dot{V}_{50}\right)$ was seen. In the individual subject, increases were small. However, maximum expiratoryo flows were not significantly improved by the injection. No significant changes in forced expiratory flows were noted after Teflon injection although all subjects with $\overrightarrow{\vec{O}}$ an $\mathrm{FEV}_{1} \%>75 \%$ before injection showed improve-3 ment. A ratio of forced expiratory to forced inspira-

Table 1 Clinical data of the patients

\begin{tabular}{|c|c|c|c|c|c|c|}
\hline \multirow[b]{2}{*}{ Name } & \multirow[b]{2}{*}{ Aetiology } & \multirow{2}{*}{$\begin{array}{l}\text { Smoking } \\
\text { history }\end{array}$} & \multirow{2}{*}{$\begin{array}{l}\text { Presenting } \\
\text { symptoms }\end{array}$} & \multicolumn{2}{|c|}{ Clinical results (subjective) } & \multirow{2}{*}{$\begin{array}{l}\text { Time betwee } \\
\text { injection and } \\
\text { second tests }\end{array}$} \\
\hline & & & & Voice & Aspiration & \\
\hline JF & Post left upper lobectomy cancer & 30 pk yr & Hoarseness & Good & & 5 weeks \\
\hline EG & Post ventriculojugular shunt & & Hoarseness & Good & & 5 weeks \\
\hline ET & Idiopathic & $\mathbf{0}$ & Hoarseness & & & \\
\hline $\mathbf{R P}$ & Neurofibroma & $40 \mathrm{pk} \mathrm{yr}$ & $\begin{array}{l}\text { Hoarseness } \\
\text { Aspiration }\end{array}$ & Good & Good & 7 months \\
\hline JBEZ & Thyroid operation for cancer & $\mathbf{0}$ & Hoarseness & Fair & & 19 months \\
\hline RB & Idiopathic & 30 pk yr & $\begin{array}{l}\text { Hoarseness } \\
\text { Aspiration }\end{array}$ & & & \\
\hline LS & $\begin{array}{l}\text { Left pneumonectomy for } \\
\text { histoplasmosis }\end{array}$ & 0 & $\begin{array}{l}\text { Hoarseness } \\
\text { Aspiration }\end{array}$ & Good & Good & 3 months \\
\hline SK & Thyroid surgery & 0 & $\begin{array}{l}\text { Hoarseness } \\
\text { Aspiration }\end{array}$ & Good & Good & 5 months \\
\hline LB & Cricoid cartilage chondroma & Unknown & $\begin{array}{l}\text { Hoarseness } \\
\text { Aspiration }\end{array}$ & & & \\
\hline HM & Post thyroid operation & 10 cigars/day & Hoarseness & Good & & 7 weeks \\
\hline DF & Thyroid operation & 0 & Hoarseness & & & \\
\hline JS & Post anterior cervical fusion & $\mathbf{0}$ & $\begin{array}{l}\text { Hoarseness } \\
\text { Aspiration }\end{array}$ & No improvement & Good & 5 weeks \\
\hline JBLA & Postoperative neck cyst & $\mathbf{0}$ & $\begin{array}{l}\text { Hoarseness } \\
\text { Aspiration }\end{array}$ & Good & Good & 8 months \\
\hline $\begin{array}{l}\text { JN } \\
\text { BS }\end{array}$ & $\begin{array}{l}\text { Laryngeal trauma } \\
\text { Idiopathic }\end{array}$ & $\begin{array}{l}\mathbf{0} \\
\mathbf{0}\end{array}$ & $\begin{array}{l}\text { Hoarseness } \\
\text { Hoarseness }\end{array}$ & No improvement & & 4 months \\
\hline
\end{tabular}


Table 2 Results of spirometric measurements and flow volume loops

\begin{tabular}{|c|c|c|c|c|c|c|c|c|c|c|}
\hline Patient & & $\begin{array}{l}F V C \\
(l)\end{array}$ & $\%$ Pred & $\begin{array}{l}F E V_{1} \\
(l)\end{array}$ & $\begin{array}{l}F E V_{1} / F V C \\
(\%)\end{array}$ & $\begin{array}{l}\dot{V} i_{\max } \\
(l / s e c)\end{array}$ & $\begin{array}{l}\dot{V} i_{\text {so }} \\
(l / s e c)\end{array}$ & $\begin{array}{l}\dot{V} e_{\max } \\
(l / s e c)\end{array}$ & $\begin{array}{l}\dot{V} e_{s 0} \\
(l / s e c)\end{array}$ & $\dot{V} e_{s o} / \dot{V} i_{s o}$ \\
\hline JF & $\begin{array}{l}\text { Pre } \\
\text { Post }\end{array}$ & $\begin{array}{l}4 \cdot 33 \\
4 \cdot 62\end{array}$ & $\begin{array}{l}91 \\
97\end{array}$ & $\begin{array}{l}2 \cdot 69 \\
2 \cdot 97\end{array}$ & $\begin{array}{l}62 \\
64\end{array}$ & $\begin{array}{l}4 \cdot 8 \\
3 \cdot 4\end{array}$ & $\begin{array}{l}4 \cdot 8 \\
2 \cdot 9\end{array}$ & $\begin{array}{l}6 \cdot 3 \\
4 \cdot 5\end{array}$ & $\begin{array}{l}1 \cdot 7 \\
2 \cdot 6\end{array}$ & $\begin{array}{l}0.35 \\
0.90\end{array}$ \\
\hline EG & $\begin{array}{l}\text { Pre } \\
\text { Post }\end{array}$ & $\begin{array}{l}2 \cdot 76 \\
2.69\end{array}$ & 77 & $1 \cdot 75$ & 63 & $2 \cdot 6$ & $2 \cdot 4$ & $2 \cdot 3$ & $1 \cdot 7$ & 0.70 \\
\hline ET & Post & $\begin{array}{l}2 \cdot 69 \\
3 \cdot 26\end{array}$ & $\begin{array}{r}75 \\
101\end{array}$ & $1 \cdot 60$ & 60 & $2 \cdot 2$ & 1.9 & $1 \cdot 9$ & $1 \cdot 7$ & 0.93 \\
\hline \multirow[t]{2}{*}{$\mathbf{R} \mathbf{P}$} & Pre & $4 \cdot 08$ & 93 & $2 \cdot 85$ & $\begin{array}{l}66 \\
70\end{array}$ & $\begin{array}{l}1 \cdot 7 \\
2 \cdot 3\end{array}$ & $\begin{array}{l}1 \cdot 6 \\
2 \cdot 2\end{array}$ & $\begin{array}{l}2 \cdot 4 \\
5 \cdot 6\end{array}$ & $\begin{array}{l}2 \cdot 0 \\
2.9\end{array}$ & $\begin{array}{l}1 \cdot 25 \\
1 \cdot 32\end{array}$ \\
\hline & Post & $4 \cdot 08$ & 93 & $2 \cdot 78$ & 68 & $3 \cdot 9$ & 3.9 & $4 \cdot 2$ & $3 \cdot 2$ & 0.82 \\
\hline \multirow[t]{2}{*}{ JB } & Pre & $4 \cdot 17$ & 127 & $3 \cdot 02$ & 72 & $3 \cdot 5$ & $3 \cdot 5$ & $6 \cdot 3$ & $3 \cdot 4$ & 0.97 \\
\hline & Post & $3 \cdot 54$ & 109 & $2 \cdot 68$ & 76 & $3 \cdot 2$ & $3 \cdot 1$ & $5 \cdot 6$ & $3 \cdot 2$ & $1 \cdot 03$ \\
\hline RB & & $4 \cdot 45$ & 98 & $3 \cdot 41$ & 76 & $4 \cdot 5$ & $4 \cdot 2$ & $11 \cdot 8$ & $3 \cdot 2$ & 0.76 \\
\hline \multirow[t]{2}{*}{ LS } & Pre & $2 \cdot 13$ & 62 & $1 \cdot 62$ & 76 & $2 \cdot 4$ & $2 \cdot 4$ & $4 \cdot 6$ & $1 \cdot 7$ & 0.71 \\
\hline & Post & $2 \cdot 15$ & 63 & $1 \cdot 61$ & 75 & $3 \cdot 4$ & $3 \cdot 3$ & 4.9 & $1 \cdot 6$ & 0.48 \\
\hline \multirow[t]{2}{*}{ SK } & Pre & $4 \cdot 45$ & 111 & $3 \cdot 49$ & 78 & $4 \cdot 2$ & $3 \cdot 9$ & $9 \cdot 2$ & $4 \cdot 3$ & $1 \cdot 10$ \\
\hline & Post & $5 \cdot 16$ & 128 & 3.83 & 74 & $5 \cdot 8$ & $5 \cdot 2$ & $10 \cdot 2$ & $4 \cdot 6$ & 0.88 \\
\hline LB & & $4 \cdot 59$ & 107 & $3 \cdot 61$ & 79 & $3 \cdot 1$ & $2 \cdot 9$ & $10 \cdot 2$ & $4 \cdot 4$ & $1 \cdot 52$ \\
\hline \multirow[t]{2}{*}{ HM } & Pre & 4.96 & 108 & 3.73 & 80 & $4 \cdot 0$ & $3 \cdot 6$ & $7 \cdot 3$ & $4 \cdot 9$ & $1 \cdot 36$ \\
\hline & Post & $5 \cdot 23$ & 114 & $4 \cdot 07$ & 80 & $5 \cdot 1$ & $4 \cdot 5$ & $8 \cdot 3$ & $6 \cdot 4$ & $1 \cdot 42$ \\
\hline DF & & $2 \cdot 52$ & 81 & $2 \cdot 03$ & 81 & $2 \cdot 4$ & $1 \cdot 0$ & $6 \cdot 2$ & $3 \cdot 0$ & $3 \cdot 00$ \\
\hline \multirow[t]{2}{*}{ JS } & Pre & $4 \cdot 81$ & 100 & $4 \cdot 11$ & 86 & $7 \cdot 0$ & $6 \cdot 4$ & $12 \cdot 8$ & $8 \cdot 3$ & $1 \cdot 30$ \\
\hline & Post & $4 \cdot 85$ & 101 & $4 \cdot 30$ & 88 & $8 \cdot 5$ & $8 \cdot 4$ & $14 \cdot 0$ & $9 \cdot 7$ & $1 \cdot 15$ \\
\hline \multirow[t]{2}{*}{ JB } & Pre & $3 \cdot 73$ & 99 & $3 \cdot 29$ & 88 & $2 \cdot 8$ & $2 \cdot 7$ & $6 \cdot 3$ & $4 \cdot 7$ & $1 \cdot 74$ \\
\hline & Post & 3.65 & 94 & $3 \cdot 10$ & 85 & $3 \cdot 0$ & $2 \cdot 9$ & $5 \cdot 1$ & 4.9 & $1 \cdot 69$ \\
\hline \multirow[t]{2}{*}{$\mathbf{J N}$} & Pre & $3 \cdot 88$ & 102 & $3 \cdot 43$ & 88 & $2 \cdot 7$ & $2 \cdot 5$ & $5 \cdot 7$ & $5 \cdot 2$ & $2 \cdot 08$ \\
\hline & Post & 3.94 & 103 & 3.46 & 88 & $3 \cdot 6$ & $3 \cdot 3$ & $6 \cdot 0$ & $5 \cdot 5$ & $1 \cdot 67$ \\
\hline BS & & $2 \cdot 73$ & 84 & $2 \cdot 55$ & 93 & $2 \cdot 8$ & $2 \cdot 6$ & $4 \cdot 2$ & $4 \cdot 2$ & $1 \cdot 62$ \\
\hline \multirow{4}{*}{ Mean } & Pre & 3.93 & & 3.00 & $76 \cdot 3$ & $3 \cdot 63$ & $3 \cdot 44$ & $6 \cdot 64$ & $3 \cdot 88$ & \\
\hline & Post & 3.99 & & $3 \cdot 04$ & $75 \cdot 8$ & $4 \cdot 21$ & $3 \cdot 94$ & 6.47 & $4 \cdot 34$ & \\
\hline & SE & 0.11 & & 0.08 & 0.81 & $0 \cdot 31$ & 0.37 & 0.34 & $0 \cdot 18$ & \\
\hline & & NS & & NS & NS & NS & NS & NS & $P<0.05$ & \\
\hline
\end{tabular}

$F V C=$ forced vital capacity; $F E V_{1}=$ forced expiratory volume in one second; $\dot{V} i_{\max }=$ maximum inspiratory flow; $\dot{V} i_{50}=$ forced inspiratory flow at $50 \%$ vital capacity; $\dot{V} e_{\max }=$ maximum expiratory flow; $\dot{V} e_{50}=$ forced expiratory flow at $50 \%$ vital capacity.

tory flow at $50 \%$ vital capacity greater than one $\left(\dot{V} e_{50} / \dot{V i}_{50}>1\right)$ (Miller and Hyatt, 1973; Yernault et al., 1973) was present in 10 of our 15 patients with unilateral vocal cord paralysis. This finding was present in four of the 10 patients who were subsequently studied after Teflon injection.

\section{Discussion}

It has been repeatedly shown that bilateral vocal cord paralysis often creates a significant variable extrathoracic airways obstruction. On the other hand, the physiological effect of unilateral vocal cord paralysis has been poorly documented. The first objective of this study was to evaluate the effect of unilateral vocal cord paralysis on maximal airflows. Ten of our 15 patients had $\dot{\mathrm{V}} \mathrm{e}_{50} / \dot{\mathrm{V}}_{50}>1$. This, according to Miller and Hyatt (1969), is suggestive of a variable extrathoracic obstruction. In three of the five patients who did not have this increased ratio, $\dot{V}_{50}$ was probably reduced by underlying bronchial disease (Bass, 1973). In this setting, the ratio $\dot{V e}_{50} / \dot{V i}_{50}$ may not adequately identify patients with decreased inspiratory flows. All eight patients with $\mathrm{FEV}_{1} / \mathrm{FVC} \%>76 \%$ had a ratio of more than one. One patient (RB) who did not meet the criteria $\dot{\mathrm{V}} \mathrm{e}_{50} / \dot{\mathrm{V}}_{50}>1$ had a spontaneous recovery of his paralysed cord. His inspiratory flows at $50 \%$ VC increased from 4.2 to $6.9 \mathrm{l} / \mathrm{s}$ (after recovery), demonstrating that unilateral vocal cord paralysis caused a reduction in inspiratory flows, and that in the presence of reduced $\dot{V}_{50}$, because of underlying

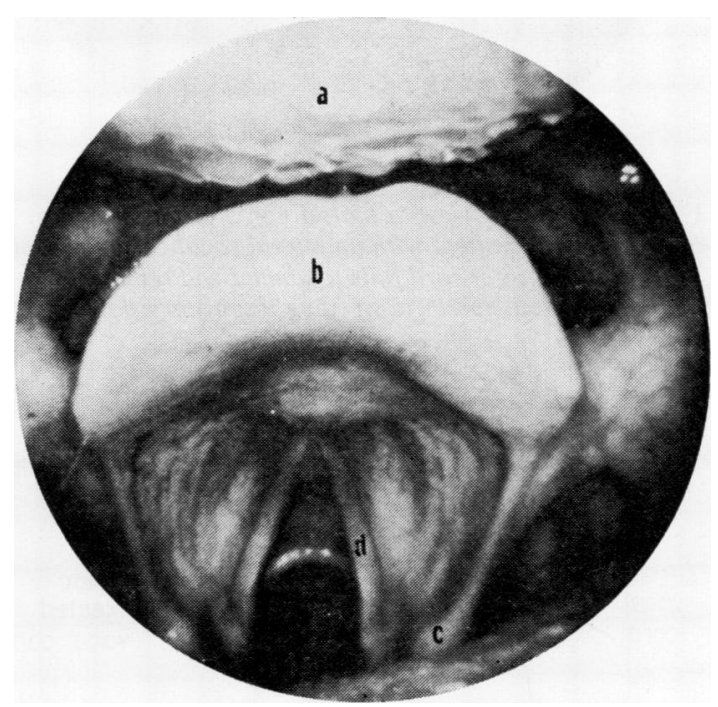

Fig. 1 Direct laryngoscopic view of normal vocal cords during forced inspiration: (a) base of the tongue, (b) epiglottis, (c) arytenoids, (d) right vocal cord. 
lung disease, the ratio $\dot{\mathrm{V}} \mathrm{e}_{50} / \dot{\mathrm{V}}_{50}$ may not identify this reduction.

Figures 1 and 2 illustrate how a unilateral paralysed vocal cord can impede inspiratory flows. During forced inspiration, normal vocal cords abduct maximally (Fig. 1). In the presence of a vocal cord paralysis, the paralysed cord is left in a resting paramedian position to impede maximal inspiratory flows (Fig. 2a). During forced expiration (Fig. 2b) the paralysed cord is deflected from its resting position and thus does not reduce expiratory airflows. Owing to the anatomy and position of the vocal cords (Lemere, 1933), a paralysed cord may act like the sail of a schooner and catch the wind in one direction. This tends to move the paralysed cord towards the

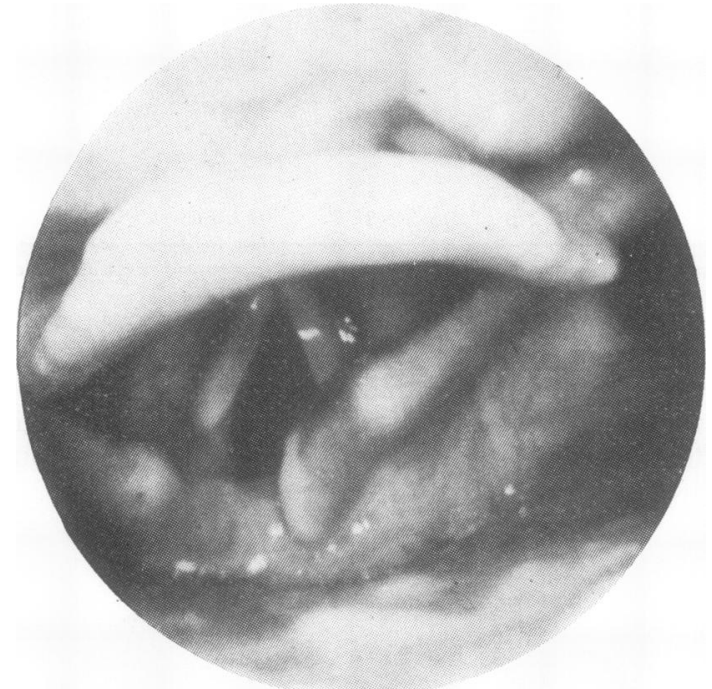

Fig. 2(a) Similar view to that in Fig. 3 during forced inspiration in a patient with unilateral vocal cord paralysis. The paralysed right cord fails to abduct and remains in a midline position, possibly impeding inspiratory flows. midline (Fig. 3). During expiration the paralysed cord $\frac{\overrightarrow{\bar{c}}}{\frac{\overline{2}}{O}}$ will be displaced laterally by the air current.

The second objective of our study was to evaluate $\frac{\overline{\bar{s}}}{\mathrm{~s}}$ the effect of Teflon injection on airflows. It seemed reasonable to assume that injecting Teflon into $a$ 을 paralysed cord would impede maximal airflow. It ises noteworthy that, in this series of patients, Teflon $\vec{\circ}$ injection did not produce significant reduction inexpiratory flow. In fact, in no patient did it produceew an expiratory pattern typical for a fixed extrathoracic airways obstruction (Yernault et al., 1973). There was no peak flow cut-off during forced expiration and no difference in peak expiratory flows before andafter surgery.

Although maximal inspiratory flow $\left(\dot{\mathrm{V}} \mathrm{i}_{\max }\right)$ ando

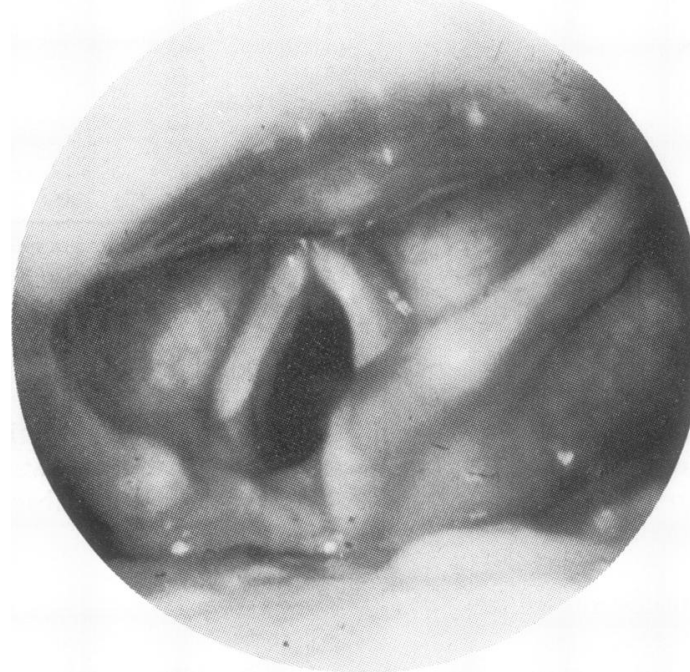

Fig. 2(b) Same patient as in Fig. 2(a). Vocal cords during forced expiration. The paralysed right cord takes a concave curvature. Airflow during forced expiration pushes the paralysed cord laterally.

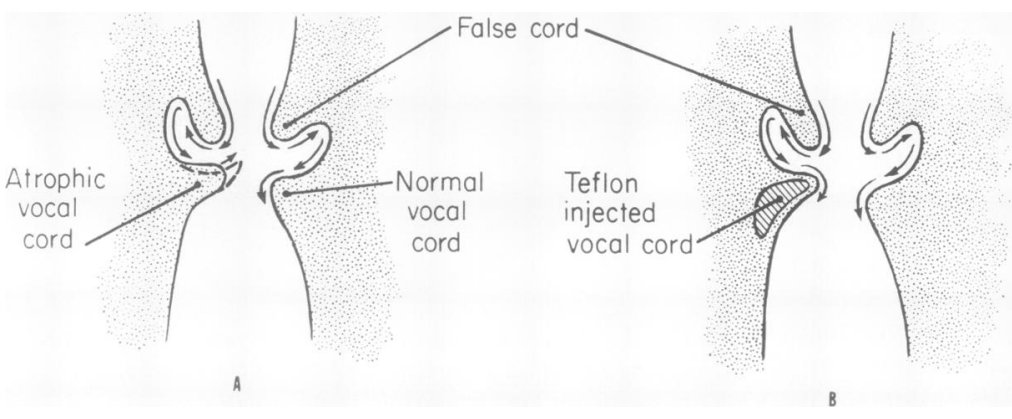

Fig. 3 Diagram representing $a$ cross-sectional view of the larynx. (left) effect of inspiratory air turbulence on the paralysed cord; (right) Teflon injection fixes the paralysed cord and may prevent this 'sail phenomenon'. 
$\dot{\mathrm{V}}_{50}$ did not significantly improve in the group as a whole, all six patients with an $\mathrm{FEV}_{1} \%$ more than $75 \%$ had improved inspiratory flows after Teflon injection. These results indicate that, in patients without evidence of underlying lung disease, an improvement in inspiratory flows after Teflon injection was demonstrable. Figure 3 shows the physical effect of Teflon injection into a vocal cord. Teflon renders the cord more rigid and may prevent the paralysed cord from moving towards the midline. This could account for improved inspiratory flows after Teflon injection.

Physiological evidence of obstruction to forced inspiratory flows is thus a frequent finding in patients with unilateral vocal cord paralysis. Teflon paste injection into a paralysed vocal cord as treatment for paralytic dysphonia is a safe procedure and exerts no long-term limiting effect on forced expiratory flows. Our data suggest that Teflon injection may actually improve forced inspiratory flow.

We thank Gary K. Diamond for technical assistance.

\section{References}

Arnold, G. (1961). Vocal rehabilitation of paralytic dysphonia. Archives of Otolaryngology, 73, 290-294.

Bass, H. (1973). The flow volume loop. Normal standards and abnormalities in chronic obstructive pulmonary disease. Chest, 63, 171-176.

Dedo, H. H., Urrea, R. D., and Lawson, L. (1973). Intracordal injection of Teflon in the treatment of 135 patients with dysphonia. Annals of Otology, Rhinology and Laryngology, 82, 661-667.

Lemere, F. (1933). Innervation of the larynx. III. Experimental paralysis of the laryngeal nerve. Archives of Otolaryngology, 18, 415-424.
Lewy, R. B. (1963). Glottic reformation with voice rehabilitation in vocal cord paralysis - the injection of Tefion and Tantalum. Laryngoscope, 73, 547-555.

Lewy, R. B. (1976). Experience with vocal cord injection. Annals of Otology, Rhinology and Laryngology, 85, 440-449.

Miller, R. D., and Hyatt, R. E. (1969). Obstructing lesions of the larynx and trachea: clinical and physiologic characteristics. Mayo Clinic Proceedings, 44, 145-161.

Miller, R. D., and Hyatt, R. E. (1973). Evaluation of obstructing lesion of the trachea and larynx by flowvolume loops. American Review of Respiratory Disease, $108,475-482$.

Rontal, E., Rontal, M., Morse, G., and Brown, E. M. (1976). Vocal cord injection in the treatment of acute and chronic aspiration. Laryngoscope, 86, 625-634.

Rubin, H.J. (1965a). Pitfalls in treatment of dysphonias by intracordal injection of synthetics. Laryngoscope, 75, 1381-1397.

Rubin, H. J. (1965b). The treatment of dysphonia due to unilateral recurrent nerve paralysis by the intracordal injection of synthetics. California Medicine, 102, 105-109.

Schiratzki, H. (1965). Upper airway resistance during mouth breathing in patients with unilateral and bilateral paralysis of the recurrent laryngeal nerve. Acta Otolaryngologica (Stockholm), 59, 475-496.

Shim, C., Corro, P., Park, S. S., and Williams, M. H., Jr. (1972). Pulmonary function studies in patients with upper airway obstruction. American Review of Respiratory Disease, 106, 233-238.

Yernault, J. C., Englert, M., Sergysels, R., and DeCoster, A. (1973). Upper airways stenosis: a physiologic study. American Review of Respiratory Disease, 108, 996-1000.

Requests for reprints to: Dr. Y. Cormier, Département de Pneumologie, Hopital Laval, 2725 Chemin Ste Foy, Ste Foy, Que 10, PQ, Canada. 